\title{
Chapter 2 \\ The Participation of Latin America and the Caribbean in International Supply Chains
}

As mentioned in the previous chapter, the concept of international supply chain is typically understood as a group of firms in different countries that work togetherfrom the design to the distribution of a product - under the coordination of a lead firm that seeks to minimize total system costs. Unfortunately, very few existing trade or foreign direct investment databases provide enough information to verify that the cross-border transactions that economists observe conform to this definition. Therefore, short of working with case studies, empirical research in this area has relied primarily on proxies to measure value-chain participation.

No single measure is likely to address all the nuances related to offshoring, and no single method is immune to some form of criticism. Therefore, in this chapter, rather than relying on a single indicator we gather various types of datasets on trade and FDI to construct a battery of alternative measures. The goal is to present as comprehensive a picture as possible of the participation of Latin America and the Caribbean (LAC) in international production networks. The various indicators provide a very consistent picture of how LAC fares relative to other regions regarding participation in global supply chains.

\section{Evidence from Intra-industry Trade Indexes}

The first measure relies on intra-industry trade indexes (see Fukao, Ishido, \& Ito, 2003; Jones, Kierzkowski, \& Leonard, 2002; Kimura, 2006). This measure is based on the premise that global supply chains are associated with sequential production links in which countries may import intermediate goods, add value, and export them to another country. As such, production linkages involve trading related goods at different stages of production. In this way, intra-industry trade can be a proxy for these processes, provided that this trade is measured at sufficiently high levels of 

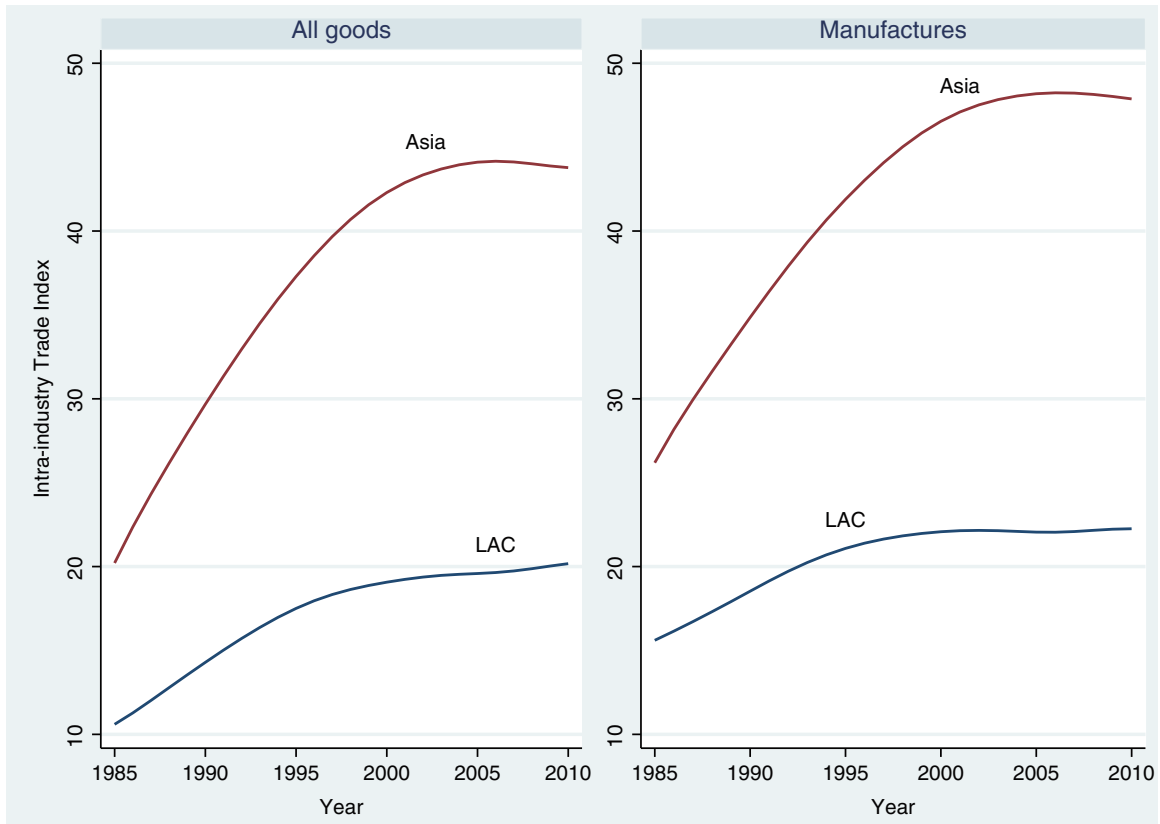

Fig. 2.1 Intra-industry trade indexes, regional averages. Source: Authors' calculations based on data from Comtrade

aggregation. For this reason, the measures of intra-industry trade constructed here are based on four-digit SITC data. ${ }^{1}$ The use of intra-industry trade measures does not come without limitations, however, since they also capture horizontal trade in the same goods, which does not necessarily reflect participation in global supply chains. Nevertheless, it is reassuring that in our results, the countries that have experienced the largest increases in intra-industry trade between 1985 and 2010 are China, Indonesia, Malaysia, Mexico, Philippines, and Thailand, all of which are highly integrated in global supply chains.

Figure 2.1 depicts the evolution of the average intra-industry trade for countries in the Asia-Pacific region and for LAC (see appendix A "Trade in Value Added and Set of Countries" for the list of countries in each region). The figure shows how intraindustry trade boomed in the Asia-Pacific region in the period 1985-2010 while increasing relatively slowly in Latin America, particularly in manufactures. This is the case whether we use all goods or only manufactures. The overall levels are also

\footnotetext{
${ }^{1}$ In particular, we use the Grubel-Lloyd index.
} 
very different, with an average measure of intra-industry trade in the Asian region twice that of Latin America. The result is in line with the general notion that the Asian countries are far more engaged in vertical specialization and cross-border production sharing than the countries in LAC. ${ }^{2}$

\section{Evidence from Trade in Value Added}

Another way to measure the participation of countries in global supply chains is to trace the value added of each source country in a globally integrated production network. Studies have applied this approach to specific goods, such as the iPod and iPhone (Dedrick, Kraemer, \& Linden, 2008) and the Barbie doll (Tempest, 1996). The information in these case studies is very rich, showing which countries participate in the supply chain of a particular good and how much value they add to its production. The studies have revealed, for example, that even though China exports the iPod, and the trade statistics report the full value of this product, the country only contributes to $3.8 \%$ of the value added, because many other countries also participate in the production. This case-by-case examination of specific international supply chains is very revealing, but the approach is so data-demanding that it would be impossible to examine every such supply chain in which a country participates. For this reason the technique is impractical for measuring the participation of countries in GVCs.

A new group of analyses are taking a different, more practical approach to tracing the value added of a country's trade flows: combining input-output tables with bilateral trade statistics (e.g., De La Cruz, Koopman, \& Wang, 2011; Hummels et al., 2001; Johnson \& Noguera, 2012a, 2012b; Koopman, Wang, \& Wei, 2008, 2014; Miroudot \& Ragousssis, 2009). The literature has evolved rapidly and has produced an array of indicators that help quantify the extent to which countries participate in cross-border production sharing.

\footnotetext{
${ }^{2}$ The advantage of using intra-industry trade indices is their simplicity: they only require data on international trade flows. Other approaches that only require trade data use the description of trade line classifications to pick up terms like "parts and components" as proxies for trade in intermediates. The main idea is to measure the percentage of trade in intermediates in total trade. These methods have been used, for instance, in Yeats (2001), Ng and Yeats (1999), and Fung, GarciaHerrero, and Siu (2009). A related approach is to employ a United Nations classification that separates goods according to their use. The classification is called the Broad Economic Categories (BEC), http://unstats.un.org/unsd/tradekb/Knowledgebase/Intermediate-Goods-in-Trade-Statistics. This method has been employed, for instance, in Baldwin and Taglioni (2011). A shortcoming of these two methods is that they tend to rely on subjective criteria on what constitute an intermediate good (see Hummels, Ishii, \& Yi, 2001). We nevertheless compare Asia and Latin America in terms of the share of intermediate inputs in total trade as measured by Fung et al. (2009). The results are in line with the findings from the intra-industry trade indexes. For instance, in 1990, exports of parts and components as a share of total manufacturing exports was on average at around $31 \%$ for Asia and $16 \%$ for Latin America. Two decades later, in 2010, this share increased to $40 \%$ in Asia and declined slightly to $14 \%$ in Latin America.
} 


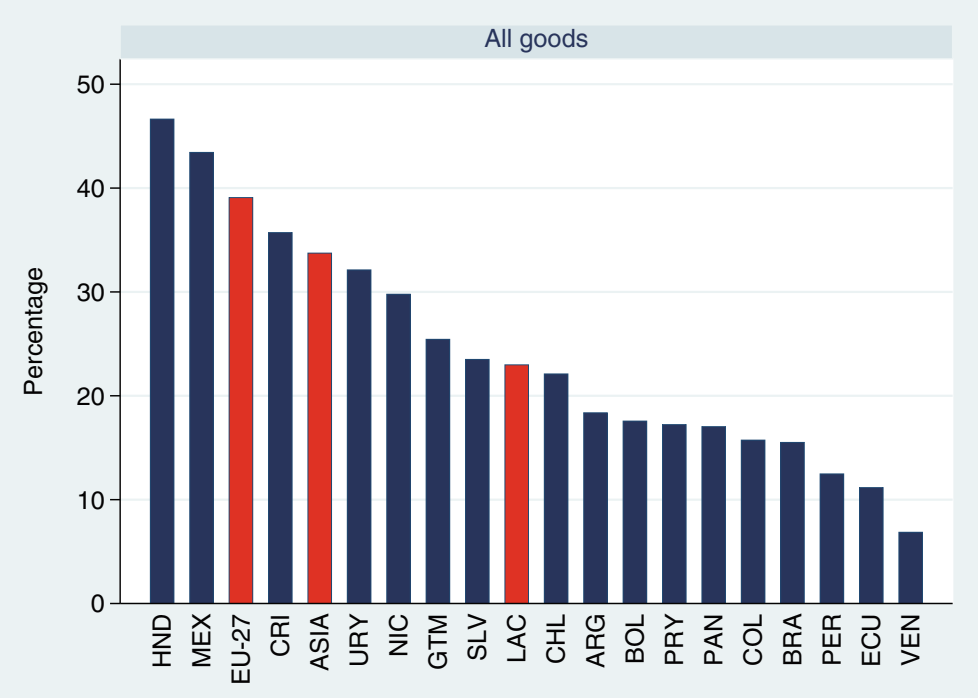

Fig. 2.2 GVC Participation through upstream linkages: foreign value added as a percentage of total exports, average 2003-2007. Source: Authors' calculations based on data from GTAP 7 and 8

In this literature, the insertion of countries in GVCs is measured with indicators that seek to capture the extent to which countries participate in a sequential chain of production activities that crosses many borders. The first indicator, called import content of exports, introduced by Hummels et al. (2001), is based on the notion of vertical specialization. Vertical specialization refers to the use of imported inputs to produce goods that are later exported, a notion that precisely captures the idea of various countries linked sequentially to produce a final good. More recently, the concept of foreign value added in exports is being used to measure vertical specialization by emphasizing value added from other countries embodied in a country's exports (Koopman et al., 2014). Foreign value added of exports is nowadays a common measure of the participation of countries in vertically fragmented production through upstream linkages.

Figure 2.2 depicts the foreign value added of exports for various Latin American countries. The measure reflects the share of foreign value added in each country's total exports. Appendix A "Trade in Value Added and Set of Countries" explains in detail the methodology and data used to develop this measure. ${ }^{3}$ The figure also shows simple averages for two comparator groups: the Asian countries and the EU-27.

\footnotetext{
${ }^{3}$ There are publicly available datasets in which similar measures of trade in value added have already been constructed for many countries in the world. These include the World Input-Output Table, funded by the European Commission and developed by the University of Groningen, and the "Trade in Value Added (TiVA) indicators," a joint OECD-WTO initiative. The coverage of Latin American countries in these databases, however, is very limited, making them unsuitable for this report.
} 
We can see that in general, the participation of Latin America in GVCs averages less than the participation of the comparator regions. The exports originating in Asia and in the EU use more intensively imported intermediate inputs than Latin America's exports. In particular, the exports of Asia and the EU use 12 and $15 \%$ points more foreign value added, respectively, than the exports of Latin America; this suggests that the countries from these two regions are more involved in sequentially linked production processes than the countries in the LAC region. ${ }^{4}$

At first it might seem surprising that a small, low-income country such as Honduras exhibits a measure of foreign value added that is higher than that of Mexico, given the latter country's extensive production linkages with North American firms in motor vehicles, electronics, aeronautics, and other industries. Clearing up this apparent anomaly provides a good opportunity to further explain what Fig. 2.2 is measuring. A foreign value added of, say, $45 \%$ indicates that this portion of the value of a country's exports comes from other nations. This value is independent of the number and/or type of industries participating in global value chains. In the case of Honduras, for example, more than a third of the total exports of the country are in textiles, predominantly T-shirts. Eighty percent of the value added in these exports are yarns, fibers, and other inputs that originate in other countries, which include the US, Mexico, China, and South Korea. This explains the high value of foreign value added for Honduras.

The example of Honduras clearly shows that global supply chains should not be associated exclusively with high-tech industries. Some countries participate in value chains of high technological content, while others, due to their comparative advantage, participate in value chains of low technological content. The issue of technological content becomes clearer when we separate the foreign value added embodied in countries' exports by the sectors generating such value added. The results, which are presented in Fig. 2.3, were calculated on the basis of the OECD classification of manufacturing sectors according to their technological content, ${ }^{5}$ which is depicted by the two graphs on the top of the figure. We complete the picture by including foreign value added generated by the primary sector (bottom left figure) and from services (bottom right figure). Note that for each country, the sum of the numbers in the four figures equals the value in Fig. 2.2.

Through this analytical lens, Mexico has much higher foreign value added generated by high and medium-technology sectors than does Honduras, while the reverse remains true for low and medium low-technology sectors. This further supports what we mentioned earlier: Honduras' exports, mainly of textiles and apparel, use mostly foreign inputs of low technological content, that is, fibers and yarns, with

\footnotetext{
${ }^{4}$ Note that there is some ambiguity in measuring GVC participation in this way. For instance, while the high value of foreign value added that is observed in Mexico certainly corroborates the insertion of this country in many international production networks, the common concern in Mexico is how to continue participating in many of these supply chains with more Mexican value added (see Box 3, Chap. 4), a trend that will lower this country's share of foreign value added of exports.

${ }^{5}$ OECD (2005).
} 

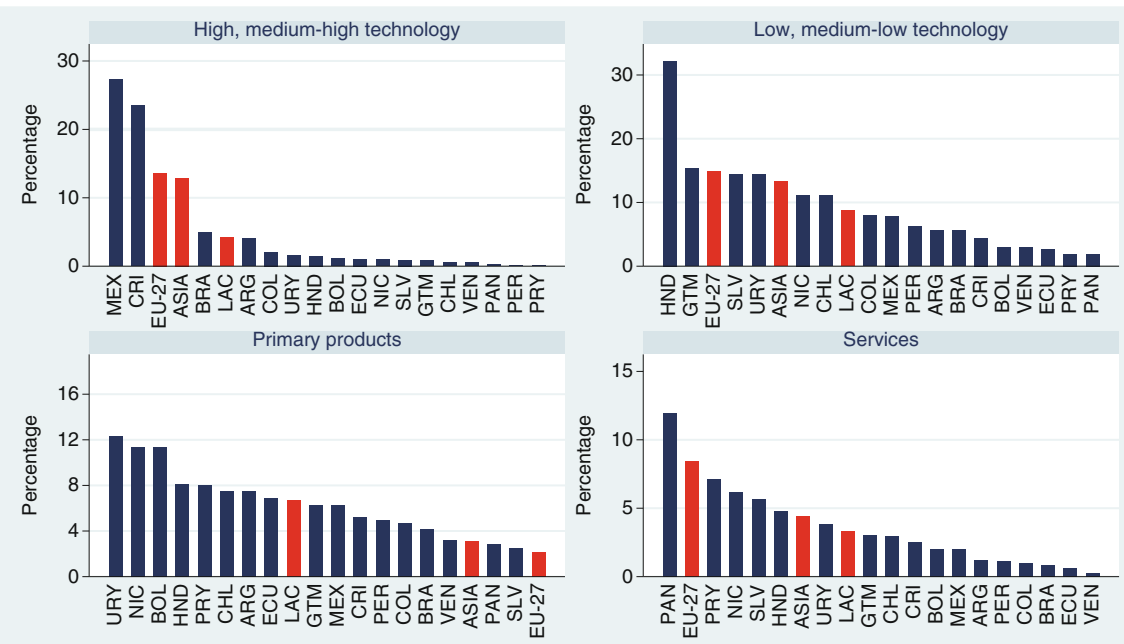

Fig. 2.3 Sector generating foreign value added in exports, average 2003-2007. Source: Authors' calculations based on data from GTAP 7 and 8

very little inputs from high-technology sectors, while the exports of Mexico largely depend on high- and medium-technology intermediate inputs.

Figure 2.3 can also be used to compare the status of Latin America as a whole with that of our comparator regions. For instance, the average values for the EU and Asia are higher than for LAC in the manufacturing sectors and in services, but the reverse is true for the primary sector. In other words, Europe and the Asia-Pacific countries are more involved than Latin America in the co-production of goods that largely utilize manufacturing sector inputs, as well as those from services; Latin America, on average, is more involved in the co-production of goods in which the main inputs come from the primary sector.

Returning to Fig. 2.2, another interesting finding is the high degree of heterogeneity that exists within Latin America, with Mexico and the countries in Central America showing the largest shares of foreign value added of exports and the countries in South America showing the smallest. This heterogeneity is in part related to differences in the patterns of specialization across the LAC region. The production of primary goods and related products tends to require fewer imported inputs than the production of many manufactures. As production processes in South American countries are typically biased toward primary products, the foreign value added of these countries' exports is particularly low.

Countries specializing in primary products are most likely to participate in the early stages of supply chains, providing inputs to other countries downstream rather than receiving inputs from abroad. To examine the extent to which the exports of a country are linked to vertically fragmented production downstream in the chain, we calculate what is known as indirect value added. This is a measure of the degree to which a country provides value added by exporting intermediate inputs that are later 


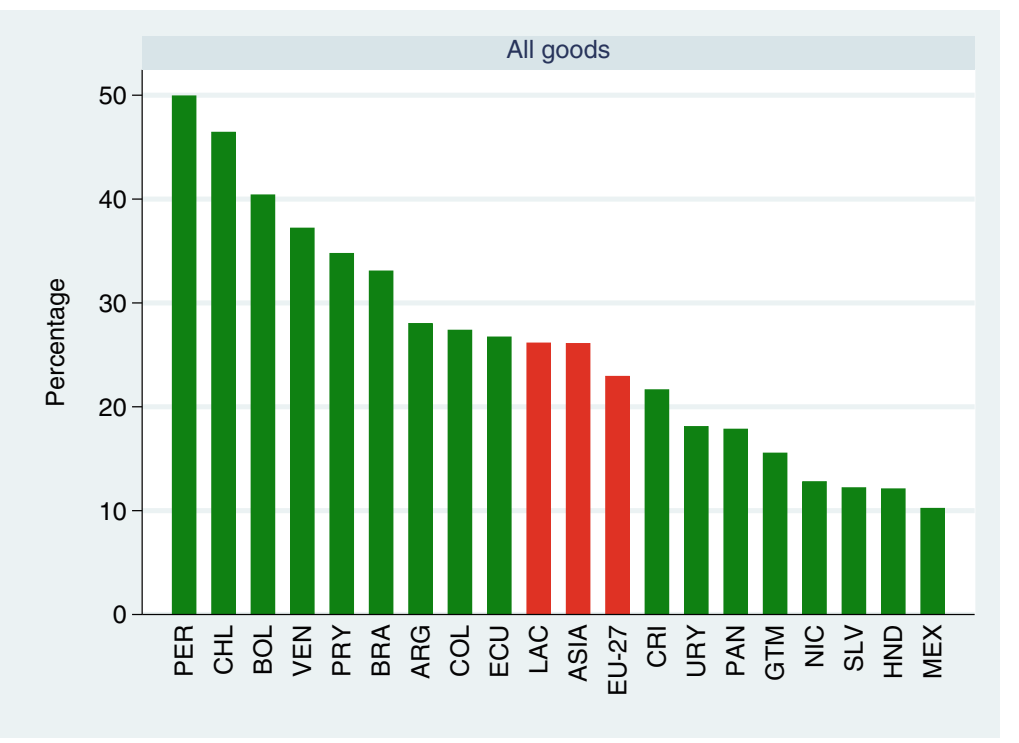

Fig. 2.4 GVC participation through downstream linkages: domestic value added used in third countries' exports, average 2003-2007. Source: Authors' calculations based on data from GTAP 7 and 8

utilized in the exports of other countries. ${ }^{6}$ This measure, which is shown in Fig. 2.4, indicates the percentage of a country's exports used as inputs in the exports of third countries. Note now that the countries in South America tend to have higher values of this measure than the countries in Central America. Note also that the average for the Latin American region is higher than for the EU and Asia. This suggests that the LAC region, on average, participates more than the EU or Asia as a supplier of value added downstream in the chain. But this is only true for the value added generated from the primary sector (as shown in Fig. 2.5), which decomposes the measure by value added generating sectors. ${ }^{7}$ This figure clearly shows that the average for Latin America is higher than the average for the EU and Asia in the primary sectors (bottom left figure), while the reverse is true in the manufacturing sectors (top figures). In other words, on average, Latin American countries participate more than Europe and Asia in international value chains as suppliers of primary inputs, while Europe and Asia participate more than Latin America as suppliers of manufacturing inputs with high, medium, or low technological content.

\footnotetext{
${ }^{6}$ Technically, indirect value added is measured as the country's value added embodied as intermediate inputs in third countries' gross exports, as a percentage of the country's gross exports (see Koopman, Wang, \& Wei, 2010).

${ }^{7}$ Note that the sum of the four values for each individual country in Fig. 2.5 is equal to the value in Fig. 2.4.
} 


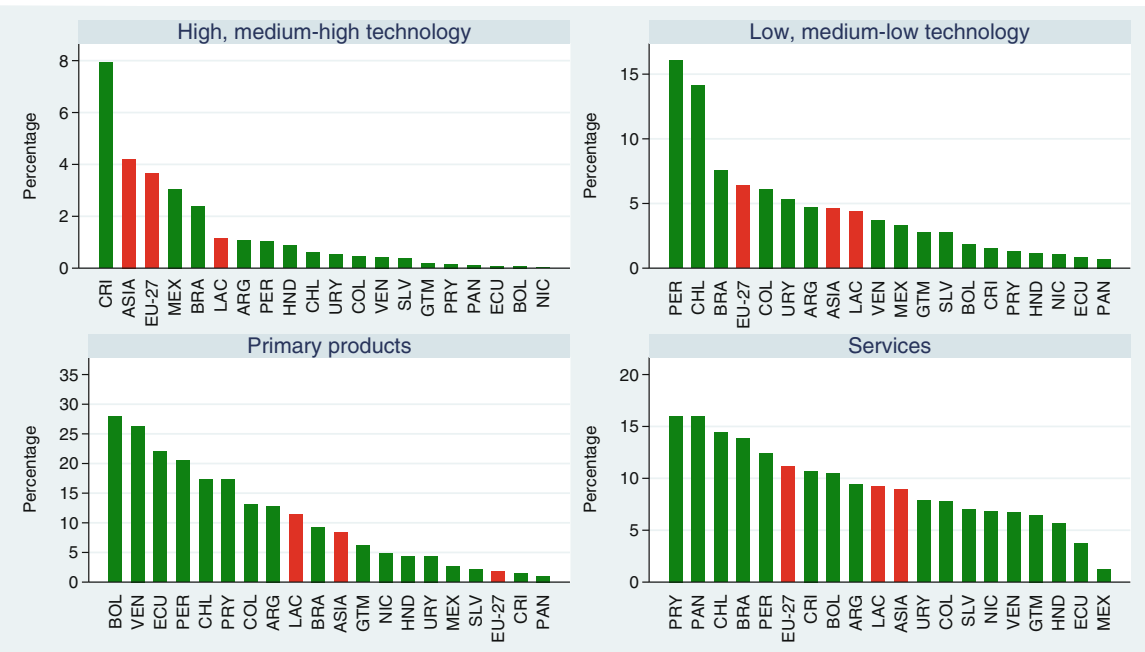

Fig. 2.5 Sector generating domestic value added used in third countries' exports, average 20032007. Source: Authors' calculations based on data from GTAP 7 and 8
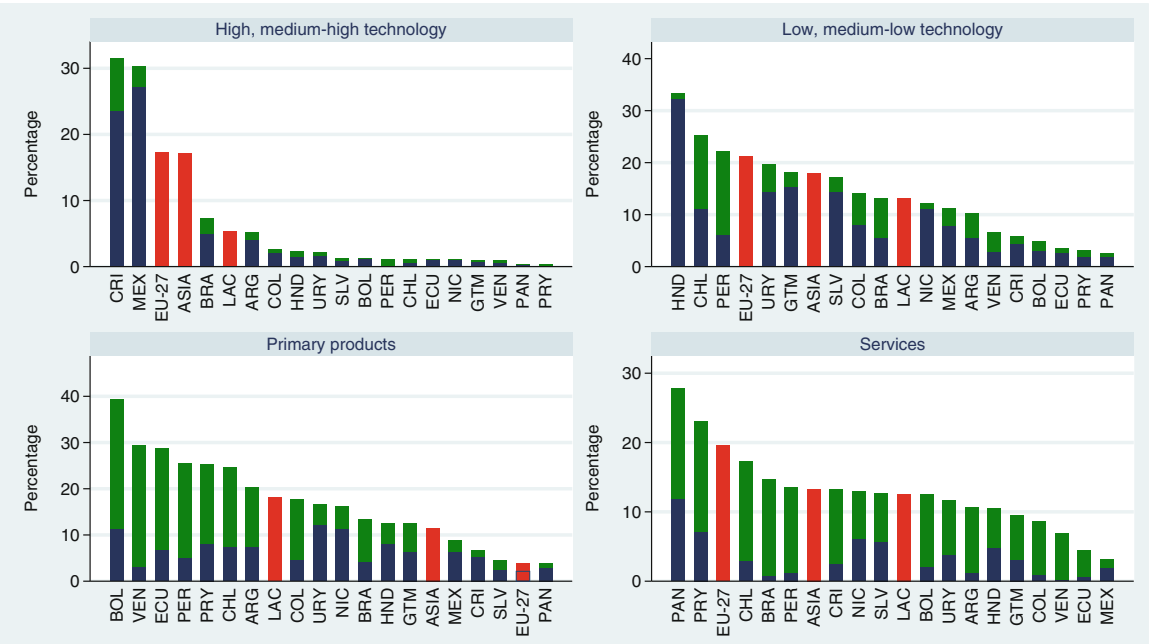

Fig. 2.6 Foreign value added (blue) and domestic value added used in third countries' exports (green), by the value added generating sector, average 2003-2007. Source: Authors' calculations based on data from GTAP 7 and 8

One way to present a combined measure of value chain participation is to add the measure of foreign value added of exports and the measure of value added used in the exports of third countries (see Koopman et al., 2014). This reflects participation through linkages both upstream and downstream. The measure calculated by the value added generating sector is shown in Fig. 2.6. Examining the averages for Latin America and 
the comparator regions clearly shows that our region in general participates less than the EU and Asia in the manufacturing (and service) segments of the global value chains, while it tends to participate more in the segments associated with the primary sector.

It is also possible to see once again how countries in Latin America differ in their participation. Costa Rica, Mexico, and Honduras, for example, participate more as recipients of foreign value added (blue segments tend to be longer than green segments), while Chile, Peru, and Bolivia participate more as providers of value added downstream in the chain than recipients (green segments tend to be longer than blue segments). Therefore, beyond the general comparison of Latin America with Europe and Asia, Latin America emerges as a region with large heterogeneity in value chain participation. On the one hand, we have countries-primarily Mexico and Central America-that process lots of foreign inputs that are incorporated in the export of goods close to their final production stages, so these countries tend to be positioned closer to the end of the supply chain. Meanwhile, the South American countries are more specialized in natural resources; they provide inputs to other countries' exports and thus are positioned more at the beginning of the supply chain.

We can construct a general measure of the position of the country in the chain by dividing the indirect value added and the foreign value added measures (see Koopman et al., 2014). ${ }^{8}$ The higher this value, the more upstream the country's position in the chain. Figure 2.7 shows the results. It is interesting to see, for

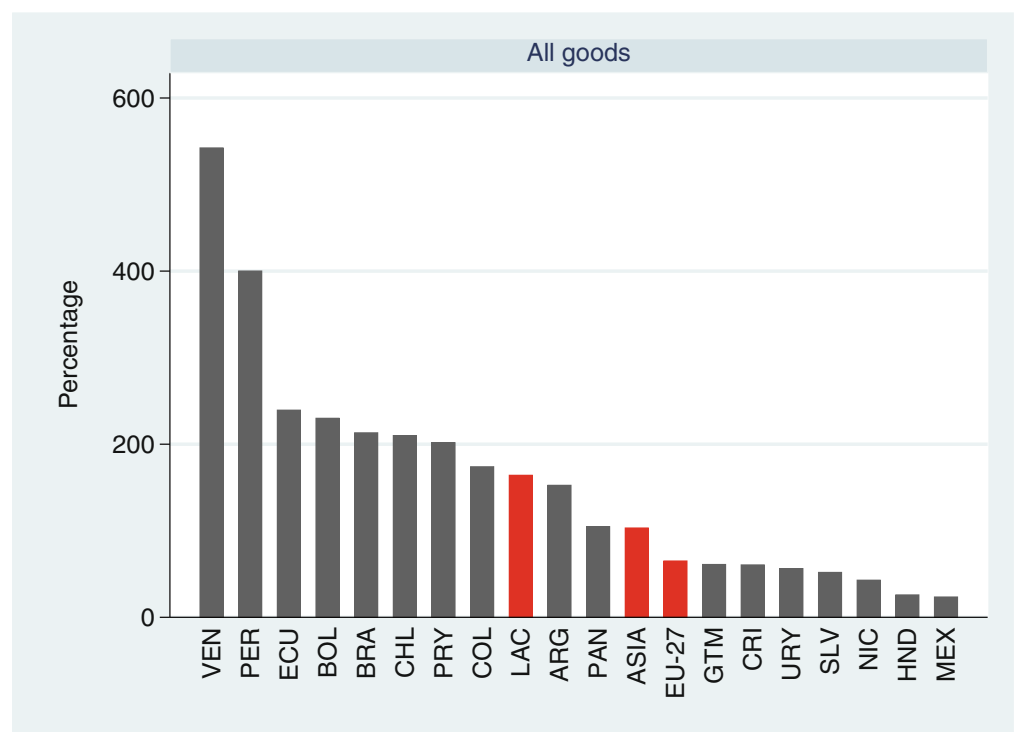

Fig. 2.7 Global value chain position, average 2003-2007. Source: Authors' calculations based on data from GTAP 7 and 8

\footnotetext{
${ }^{8}$ This measure is the percentage of a country's exports used as inputs in the exports of other countries, divided by the foreign value added of the country's exports.
} 
example, that the value added from Peru used as inputs in third countries' exports is four times greater than the value added from other countries employed in Peruvian exports. Figure 2.7 shows clearly the heterogeneity within the region that we mentioned before, with Mexico and Central America more at the end of supply chains and South America more at the beginning. Latin America as a whole is positioned more upstream in global supply chains than the comparator groups due to the average specialization of the region towards natural resource intensive sectors.

Summarizing the results, there is considerable heterogeneity within Latin America, in which Central American countries and Mexico participate more in downstream segments of global value chains while South American countries are relatively more active in upstream segments, mainly due to their specialization in primary sectors. Even within the group of countries participating in downstream supply chain segments, some economies specialize in value chains of low technological content while others focus more on high-technology segments. In general, however, the various indicators confirm the general perception that Latin America tends to participate less than other regions in global value chains, particularly in value chain segments related to the manufacturing sector.

Two obvious questions arise from these findings: Can countries in the region increase their participation in global value chains? And can they participate in segments of higher value added? Note that these questions do not necessarily imply that the countries should target industries of high technological content, such as electronics. Instead, the questions point to the potential even for countries with comparative advantages within certain industries to identify segments of high value that have not been exploited. For instance, Honduras has traditionally been linked to the low-technology global value chain in which the production of T-shirts is one of the main staples. Today, Honduras can use knowledge developed through the supply chains of exporting T-shirts to enter new export segments of the textile industry, such as parachutes. The same can be said for the primary sector. Abundance of natural endowments and specialization in primary goods does not preclude countries from adding value in natural resource-related supply chains. These are without doubt important issues for the Latin American region that we will address in later chapters of this report.

We can also use this methodology to examine the contribution of the different world regions to global value chain participation. The idea is to see how much participation in value chains occurs among countries of the same region and how much takes place with countries in other regions. For instance, do countries in Europe engage in international supply chains mostly with other European countries? Or are their production networks spread evenly across the globe? Figure 2.8 shows that the participation in international production networks is more intense among countries of the same region than with other regions. The within-region participation in the EU, Asia-Pacific, and LAC is $51 \%, 47 \%$, and $29 \%$, respectively. In each case, the within-region participation is always the highest. This result suggests that global value chains do not cope well with vast distances, an issue that will recur in the rest of this report. 


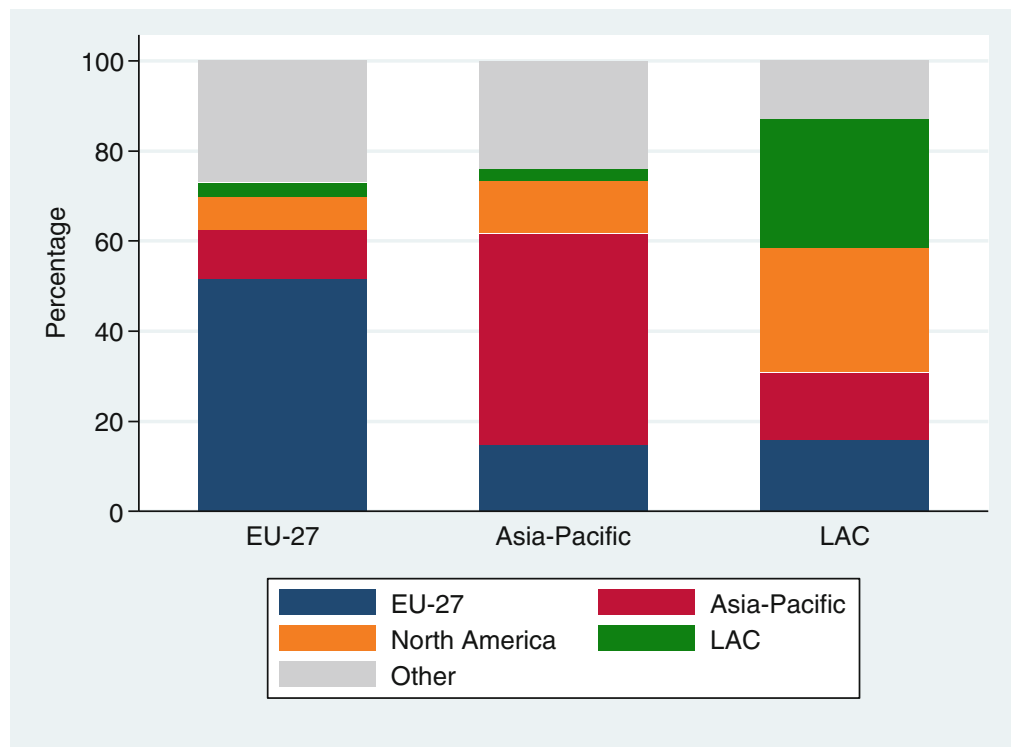

Fig. 2.8 Regional contribution to foreign value added, average 2003-2007. Source: Authors' calculations based on data from GTAP 7 and 8

\section{Evidence from FDI Data}

An alternative way to examine the participation of countries in global supply chains is to look at data on FDI. True, many companies offshore part of their production processes through independent suppliers and not through FDI. Nevertheless, multinationals still play an important role in many global production networks, and looking at their locations gives us an additional opportunity to analyze the extent to which Latin American countries take part in cross-border production sharing.

We employ the Dun \& Bradstreet (D\&B) Worldbase dataset, which covers more than 200 countries and territories and has been used in academic studies for various purposes. ${ }^{9}$ For each firm in this dataset there is information on an array of variables, including location (city/country), industry of production, and family tree (the firm's parent and other related parties). We follow Alfaro and Charlton (2009) in identifying

\footnotetext{
${ }^{9}$ For instance, the comparison of size and diversification patterns of foreign investment in North America (Caves, 1975), the development of microdata sets on enterprises (Lipsey, 1978), the effect of bank credit availability and business creation (Black \& Strahan, 2002), the relationship between financial development and vertical integration (Acemoglu, Johnson, \& Mitton, 2009), the patterns of intra-industry and inter-industry FDI (Alfaro \& Charlton, 2009), and the relationship between foreign ownership and establishment performance (Alfaro \& Chen, 2011).
} 
whether the relationship between a parent company and its subsidiary is horizontal (the parent and the subsidiary produce the same good), vertical (the subsidiary produces an input for the parent), or complex (the relationship is both horizontal and vertical). The methodology compares the industry codes (at the four-digit SIC level) of both parents and affiliates to examine whether they produce the same good and/or whether the affiliate is a supplier to its parent. The latter is determined by using the industry codes in combination with an input-output table to identify whether the industry of the subsidiary corresponds to an upstream industry of the parent's output. ${ }^{10}$ One potential shortcoming of this approach could be uneven coverage of a worldwide company dataset, particularly in developing countries where information is harder to obtain. Appendix A "FDI Dataset", however, provides details about the extensive checks and quality controls used by $\mathrm{D} \& \mathrm{~B}$ to gather information and presents a test that appears to validate the coverage of the data.

Figure 2.9 shows the network of parents and their vertically linked subsidiaries around the world. The size of the circles in each country indicates the total number of parent companies located in that country that own vertically linked subsidiaries in other countries. The thickness and color intensity of the lines represent the number of bilateral vertical subsidiaries between each parent country and a corresponding host country. Several interesting insights emerge from this figure. First, most multinational parent companies are located in industrialized countries, and a very large number of their foreign affiliates are also located in the industrialized world. This is consistent with the general finding in the literature that most FDI is of the North-North type. This is also consistent with recent evidence indicating that what had been thought to be horizontal FDI flows among developed nations are actually vertical FDI flows (Alfaro \& Charlton, 2009). Our evidence is also consistent with results from a US survey: data from Fortune 1,000 companies show that more than $60 \%$ of all the offshoring of these companies is conducted in industrialized economies (Sturgeon, Nielsen, Linden, Gereffi, \& Brown, 2012). ${ }^{11}$

On a regional level, well-defined supply chain networks in Europe are led by Germany, those in Asia are led by Japan, and networks in North America are led by the US, which also has very strong links with the EU and Asia. With the exception of Mexico and possibly Brazil, LAC-like Africa-remains pretty much on the sidelines when it comes to participating in production networks led by multinationals.

\footnotetext{
${ }^{10}$ Similar to Alfaro and Charlton (2009) we use the Bureau of Economic Analysis 1987 benchmark input-output table and employ alternative thresholds of the input-output total requirements coefficient.

${ }^{11}$ It has been noted that supply chains have been prevalent among nearby high-wage countries, such as the US and Canada, or Germany and France. The trade in these supply chains is typically based on exploiting scale economies rather than on wage gaps. For instance, a firm in a developed country dominates the market of a particular input through continuous learning-by-doing and scale economies. This has been referred to as "horizontal specialization" (Baldwin, 2012).
} 


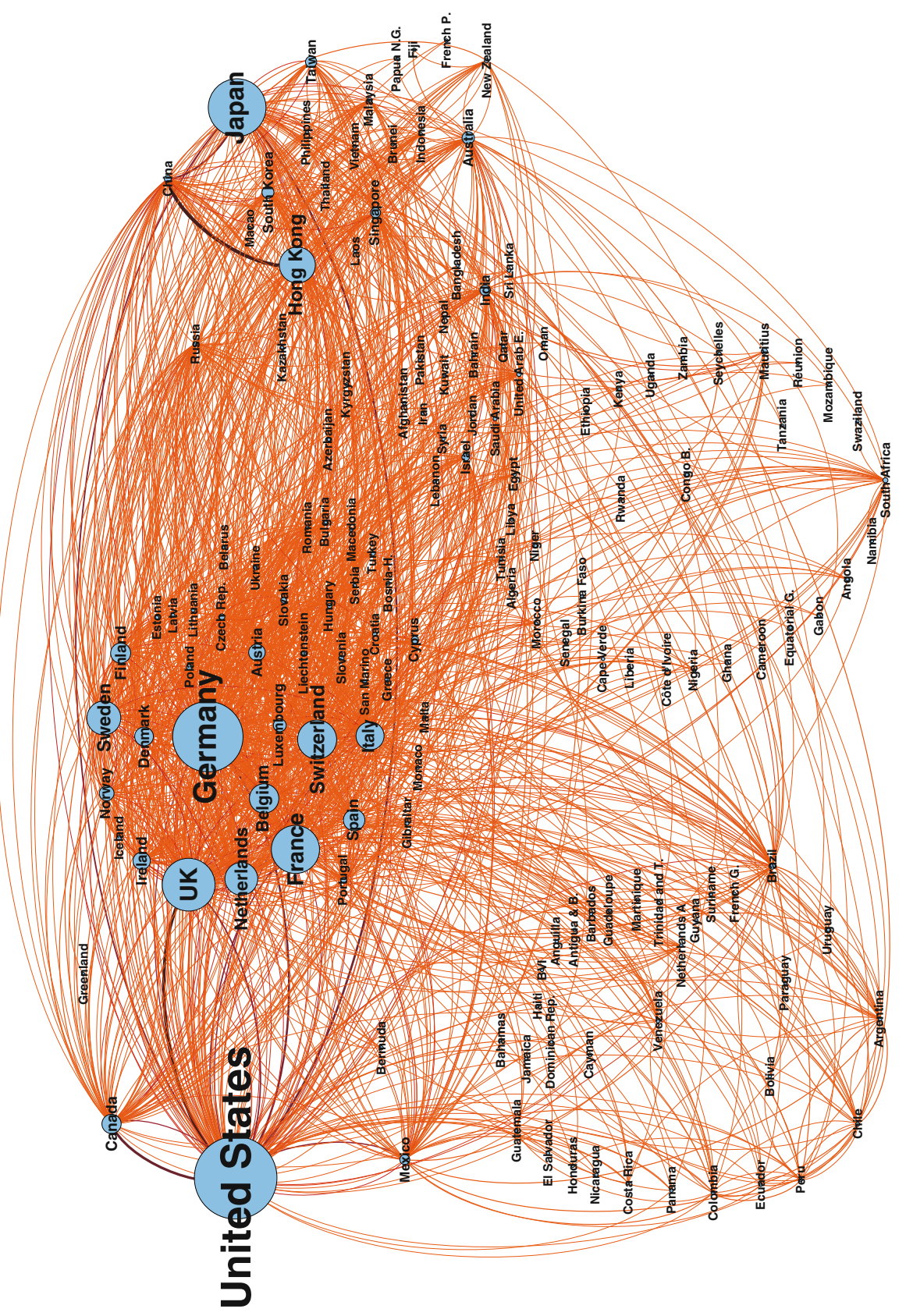




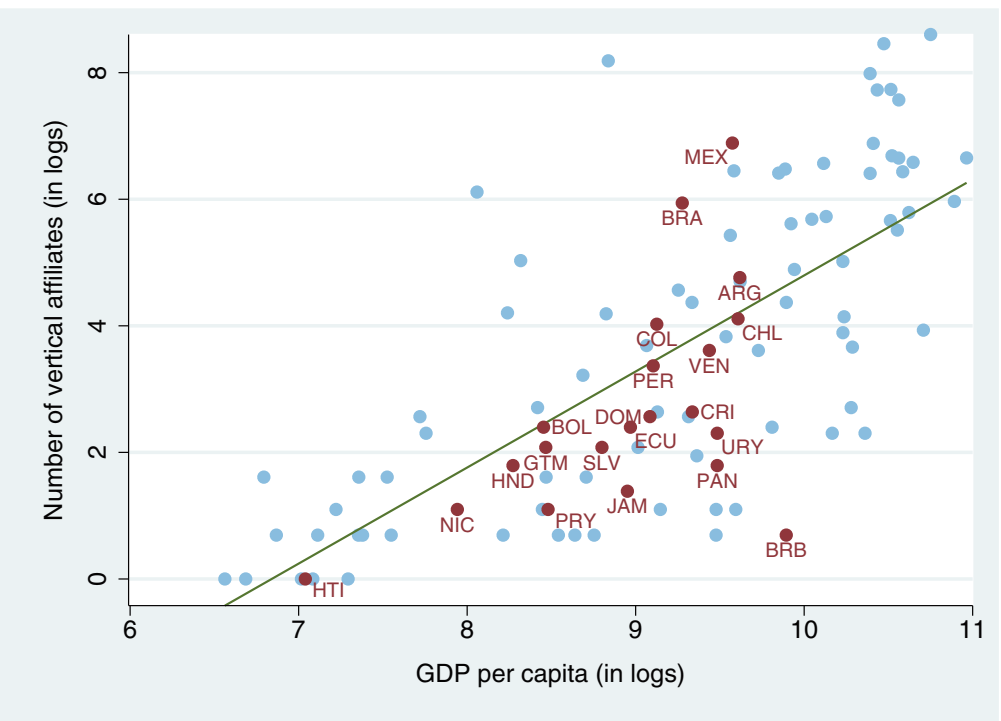

Fig. 2.10 Number of vertically linked foreign subsidiaries and income. Source: Authors' calculations based on data from Dun \& Bradstreet

Figure 2.9 only provides crude evidence on the location of vertical FDI and does not control for factors such as differences in the level of development. One could expect, for instance, that more developed countries would host more foreign subsidiaries than less developed countries. In controlling for differences in per capita income, Fig. 2.10 indeed shows that there is a clear positive relationship between the level of income of the country and the number of vertical subsidiaries that it hosts. However, most countries in Latin America fall below the trend line, indicating that the number of foreign subsidiaries is lower than what should be expected from their level of development. In other words, even after accounting for differences in income per capita, the participation of most countries in the region seems to be low.

\section{Evidence from Trade in Services}

International trade in services is a growing trend in global commerce. In particular, the offshoring of business functions such as accounting or IT services is part of the same phenomenon of international fragmentation in which firms decide to locate part of their production of components and/or services in different countries. ${ }^{12}$

\footnotetext{
${ }^{12}$ Note that the offshoring of services does not involve all trade in services. Some trade in services might not be related to the fragmentation of production.
} 

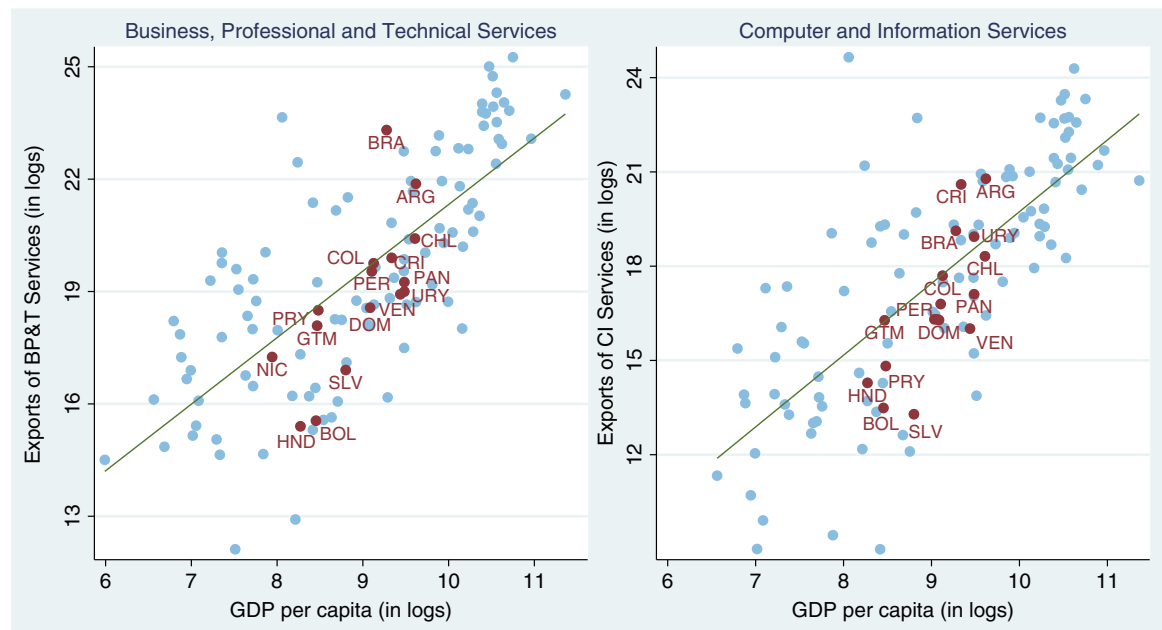

Fig. 2.11 Exports of selected offshoring services and income. Source: Authors' calculations based on the UN's Service Trade Database

We will now examine the level of Latin America's participation in the offshoring of such services and compare it with the participation of other regions.

We will make this comparison through an analysis of two service categories that are intrinsically related to global supply chains: "computer and information services" and "miscellaneous business, professional, and technical services." 13 The second category includes services related to business process outsourcing and knowledge process outsourcing. ${ }^{14}$ The data are taken from the UN's Service Trade Database.

Figure 2.11 shows the positive relationships between exports of these services and the countries' GDP per capita: more developed countries tend to export more of these services. Also clear from the figure is that most countries in the region underperform the respective trend lines, suggesting that Latin American countries tend to export less of these services than would be expected given their level of economic development. In the next chapter, we present a model that indicates the potential factors behind this subpar performance.

\footnotetext{
${ }^{13}$ The categories are part of the Extended Balance of Payment Classification, which is commonly used in the service trade databases of the UN, OECD, and IMF.

${ }^{14}$ This category includes the following: legal services; accounting, auditing, bookkeeping, and tax-consulting services; business and management consultancy and public relations services; advertising, market research, and public opinion polling; research and development; architectural, engineering, and other technical services; and other business services.
} 


\section{Recapitulating}

Most of the indicators we used to examine the participation of LAC in global value chains present a similar picture: LAC's participation generally tends to be low relative to other regions. However, there is also significant heterogeneity within the region. For instance, Mexico and countries in Central America are more engaged in production networks, particularly with North America, and tend to participate in the final stages of production networks. For their part, countries in South America typically enter supply chains in the early stages. A set of clear factors explain at least some of these differences. For instance, proximity to the US makes Mexico an ideal recipient of offshoring activities. Likewise, the sheer abundance of natural resources in South America biases countries to participate in more upstream stages of supply chains. Proximity, the endowments of natural resources, and the relative abundance of different classes of labor are obvious drivers behind the levels and types of participation in supply chains. But they are not the only drivers. The next chapter uses a more rigorous analysis to identify a more complete spectrum of factors behind the region's relatively subpar participation in international supply chains.

Open Access This chapter is distributed under the terms of the Creative Commons Attribution Noncommercial License which permits any noncommercial use, distribution, and reproduction in any medium, provided the original author(s) and source are credited. 